\title{
Rill treatments to enhance nutrient rich soil, a case study
}

\author{
Subash Thanappan*, Shashidhara Ranganath Hosamani, Mahesh Naganahalli Chandrappa \\ Department of Civil Engineering, Ambo University, Ambo, Ethiopia
}

\begin{abstract}
Received:
July 23, 2019

Accepted:

February 20, 2020

Published:

April 25, 2020

Abstract

This article mainly focuses on the soil conservation practices to counteract the soil degradation and to maintain the soil nutrients and organic matter. As the study area is highly prone to the soil erosion, the comparison study was initiated for the rill treatment with the help of sweet gum balls, riprap (different sizes of stones), mulch with coconut shells, bermuda grass with polyacrylamic (PAM) and a control. Five different rills of same size including an untreated control with four different materials used for making the protective covers were experimented initially using the triangular notches of $60^{\circ}$ by maintaining the actual discharge of $0.001379 \mathrm{~m}^{3} \mathrm{sec}^{-1}$. The rills were continuously kept under the visual observations for about two years which includes two monsoon seasons for each year. The changes in the size of the rills after every 4 rainy seasons are documented. The results of the experiments showed that the erosion control capacity of various protective covers are $68.4,57,51.2$ and 44.8 respectively with the ingredients riprap, sweet gum ball, bermuda grass with PAM and the mulch with the coconut shells.

Keywords: Analytical hierarchy process, Mulch, Polyacrylamic, Rip rap, Soil erosion, Visual observations

\section{How to cite this:}

Thanappan S, Hosamani SR and Chandrappa MN, 2020. Rill treatments to enhance nutrient rich soil, a case study. Asian J. Agric. Biol. 8(2):186-193.

*Corresponding author email: thanappansubash@gmail.com

DOI: https://doi.org/10.35495/ajab.2019.06.242

This is an Open Access article distributed under the terms of the Creative Commons Attribution 3.0 License. (https://creativecommons.org/licenses/by/3.0), which permits unrestricted use, distribution, and reproduction in any medium, provided the original work is properly cited.
\end{abstract}

\section{Introduction}

A substance at the interface between the atmosphere, lithosphere, hydrosphere, and biosphere and which is non-renewable source with mixture of minerals, organic matter, gases, liquids, and variety of organisms, existing on the surface and supports plant life on earth is said to be Soil. Soil, the loose top surface layer of earth, also called as the Skin of the Earth and a natural body act as a medium for the growth of plants; act as the means of water storage, supply and purification; a modifier of Earth's atmosphere and act as a habitat for organisms. This life supporting top surface of the earth is a precious gift of nature to the mankind because of the reason that soil is basis of all agriculture. Besides, environmental, public health and threats to land use patterns, the prevalent cause of soil erosion is that it brings massive changes in the physical, chemical and biological characteristics of soil. The physical and mechanical erosion is caused by the particulate weathering of sedimentary and metamorphic rocks or soil into sediment. The process of dissolution of the soil or rock material into bankrupt, followed by a flow away, is the major cause for the chemical erosion. The eroded sediments or solutes caused by physical, mechanical or chemical erosion may be forced to migrate to a distance of a few millimeters or thousands of 
kilometers. Also, soil erosion occurs when soil particles are carried by water and wind and deposited somewhere else. Though soil erosion is a natural occurrence, human activities and severe climatic factors amplify the soil erosion by 10-40 times universally. Human interaction in mountainous sites for intensive farming practices causes both 'on-site' and 'off-site' problems. The loss of the nutrient-rich top soil layers caused by the erosion results in on-site problems such as decrease in agricultural productivity, sedimentation of water ways, Eutrophication, desertification and sediment -related damage to roadways, residential buildings and etc. Cultivation has been expanded to steep sloping lands in many developing countries in the world due to increasing population, which causes major types of environmental degradation with direct consequences in terms of soil fertility decrease and water availability. The top layer of soil is the most fertile one because it contains the organic nutrients. When a raindrop hits soil that is not protected by a cover of vegetation and where there are no roots to bind the soil, it has the impact of a bullet. Hence, in modern days, soil erosion is one of the most important environmental hazards. Siltation of reservoirs due to soil erosion minimizes the life of the project and affects the hydroelectric power generation. Erosion from sloping lands cause serious problems downstream, silting of dams and streams, frequent flooding, damage to irrigation and hydro-electric schemes etc. Farmer's practices over the irrigational fields in tropical and semi-arid areas, leads to soil fertility loss and hence brings on negative impacts to environment. Soil erosion is regarded as one of the major cause of land degradation, and as such poses severe limitations to sustainable agricultural land use. Soil erosion tragically affects the quality and quantity of soil, water and hence its productivity. Thus, flora and fauna on the earth surface is also affected. On sloping land, erosion is active which disturbs the soil physical factors by removing the top soil layer and is a kind of desertification and the most serious environmental discrepancy that could highly affect the nutrients and the organic matters in the soil and threatens the soil resources (Govers et al., 2017). The natural soil erosion, in turn, highly affects any kind of land forms and therefore it is a major threat to the land use patterns especially in the mountainous environment (Amashi et al., 2018). The current study area, Thekkumalai Hill Base, Agesteeswaram Thovalai belt, Kanyakumari District, Tamil Nadu,
India, is an agri-fed region having an average slope of 3 to 4 degree. The study area enjoys two monsoons namely, south-west monsoon (June to September) and north -east monsoon (October -November) with an average rainfall intensity of $499 \mathrm{~mm}$. Due to the sloppy terrain nature in the study area, it is graspable that the run-off will be the prevalent erosion agent as compared to the other factors. Hence, it is projected to use some of the locally available protective covers on the top soil to control the soil erosion and degradation (Mehlhorn and Alqusaireen, 2013). The major protective covers used in the current study include sweet gum balls, rip rap, mulch with coconut shells and bermuda grass sod. The use of sweet gum balls has the modern benefits as it is the most environment friendly pesticide against the pathogenic fungi (Jody et al., 2015). According to Bhanooduth Lalljee, mulching act as cushions for soil conservation and is a best agricultural technology (Lalljee, 2013). As the chosen study area is a hill base terrain with the slope of more than 2.5 degree, it is comprehensible that runoff should be the prevalent erosion agent when comparing with the others. Thus, it is anticipated that by using the protective cover on the soil, the erosion can be controlled. It is weighed up that such protective covers should act as a barrier to the erosion. It is experimented to resist the erodibility rate due to runoff by creating five different rills. To create the protective covers in those rills, sweet gum ball, rip rap, bermuda grass, coconut shell and mulch were experimented which are functional against erosion as well as locally available tremendously. Five different rills each with five different functional materials said above were periodically detected with visual observations in comparison with an untreated rill. The degree of erosion control by different agents were compared and documented.

\section{Material and Methods}

It was a motivation inspired by the visual common observations to decide to conduct a study on chosen area for the reasons that;

The average slope of the chosen study area is $3-4$ degree, focussed with the slope, the annual average rainfall of $499 \mathrm{~mm}$.

The region was found with a number of gullies approximately in the distribution of 10-15 per square kilo meter.

- Brick making activities in the region. 
- Existence of rock crushing plant.

- Increasing colonization and deforestation.

Expert opinions, land users' opinions, field monitoring, observations and measurements are the common methods used to initiate the assessment land degradation, which is actually called the reconnaissance survey. The reconnaissance survey was to ascertain the slope of the terrain, the average rainfall intensity, the identification of gullies, and the existing human activities etc. (Subash et al., 2017). The base map of the study area was created using Google maps and local body administrative maps. The secondary data were collected from concerned administrative bodies of land and water, official documents, government data sheets, related books and journals. The questionnaires were used to collect information from local farmers and local merchants. More valuable information was collected from the experts and the concerned water and land administrations by personal interview. The data collected from the farmers practicing agriculture in the study area indicates that there is a steep decline in the agricultural productivity and their income year by year. This fact gives enough motivation that a thorough and detailed scientific study is needed to suggest the farmers and an appropriate and suitable soil stabilization techniques to conserve the soil and as well as the agricultural practices. The soil samples were collected from thirteen trail pits of size $1 \mathrm{~m}^{2}$ area at a depth of $2 \mathrm{~m}$ as suggested by the pioneer researcher (Subramani et al., 2014) and tested for its physical characteristics to identify the soil erodibility rate. The testing was done on air-dried samples in a short period of time for a relative consistent analysis on both the physical and chemical characteristics as suggested by the pioneer researcher (Lawrence et al., 2016; Subash et al., 2017).

For hydrometer analysis, the control solution was prepared such that $125 \mathrm{~mL}$ solution of $40 \mathrm{gL}^{-1}$ sodium hexametaphosphate solution and $875 \mathrm{~mL}$ of water. All the physical tests on soil samples were conducted as per the IS standard. For the rill treatment using bermuda grass, PAM was made powdered and mixed with water to make a liquid form.

The soil samples collected were analyzed for ascertaining the soil gradation through sieve analysis and hydrometer analysis, soil $\mathrm{pH}$, electric conductivity and for analyzing the nutrients level of soil samples following the standard procedure at Soil Testing Laboratory, Vettornimadam, Nagercoil, Kanyakumari District, Tamil Nadu, India. Sieve analyses revealed that all the samples were of Sandy Clay Loam (SCL). Consistency tests on the samples disclosed that the degree of plasticity was moderately slight, low or medium which showed that the study area is highly prone to erodibility. Compaction test showed that bulk density range was higher than the prescribed standard which indicated that plant roots find it difficult to penetrate the soils, and this reduces infiltration and increases overland flow and results to erosion. The specific gravity of the samples, which is the indicator water holding capacity and hydraulic conductivity, were found to be medium to high which could encourage infiltration and reduce surface runoff and soil loss. The porosity levels of most of the samples were found to be high which indicated the lack of cohesion within the soil particles. Thus, the study area was prone to the effects of erosion agents. Permeability of the samples was ranging from relatively high to high. The high permeability reduces the shear strength of the soil and consequently makes the soil more susceptible to erosion. The compressive strength of samples found from unconfined compressive strength test showed that the most of the locations were prone to highest soil loss and of few were prone to medium to less soil loss.

Table-1: Assessment of predicted soil loss

\begin{tabular}{|c|c|c|c|c|c|c|}
\hline No & Sand & Silt & Clay & K & R & PSL \\
\hline 1 & 67 & 6 & 27 & 0.03 & 249.5 & 16.77 \\
\hline 2 & 78 & 0 & 22 & 0.04 & 249.5 & 22.36 \\
\hline 3 & 68 & 4 & 28 & 0.026 & 249.5 & 14.53 \\
\hline 4 & 76 & 2 & 22 & 0.035 & 249.5 & 19.56 \\
\hline 5 & 75 & 5 & 20 & 0.04 & 249.5 & 22.36 \\
\hline 6 & 72 & 6 & 22 & 0.035 & 249.5 & 19.56 \\
\hline 7 & 67 & 9 & 24 & 0.032 & 249.5 & 17.88 \\
\hline 8 & 69 & 8 & 23 & 0.033 & 249.5 & 18.44 \\
\hline 9 & 69 & 4 & 27 & 0.027 & 249.5 & 15.09 \\
\hline 10 & 64 & 10 & 26 & 0.028 & 249.5 & 15.65 \\
\hline 11 & 75 & 5 & 20 & 0.04 & 249.5 & 22.36 \\
\hline 12 & 79 & 1 & 20 & 0.04 & 249.5 & 22.36 \\
\hline 13 & 76 & 4 & 20 & 0.04 & 249.5 & 22.36 \\
\hline
\end{tabular}

The shear strength of soil particles is closely related to erosion, that is, an increase in shear strength normally generates an increase critical shear stress for erosion and a decrease in the erosion rate. The clay content of the samples was less than $32 \%$ by which the absence 


\section{Subash Thanappan et al.}

or less percentage of clay content in the soil particles reduces the tendency to bind them together and susceptible to more erosion. The USLE is a tool to support soil conservationists in farm planning, mainly to calculate approximately soil loss on specific slopes in specific areas. If the estimated soil loss exceeded acceptable limits, the USLE was used to guide the conservationist and farmer in choosing a practice or practices that would control erosion adequately while meeting the needs and wishes of the farmer. Thus, the USLE helped to mold erosion control practices in the specific sites. The erodibility factor $(\mathrm{k})$ was calculated using the Revised Universal Soil Loss (RUSLE) concept shown in equation 1 and the assessment of predicted soil loss was carried out and recorded as shown in Table 1 . The results output of the physiochemical test were used to produce a composite map screening the erodibility rate (Figure 2) of the individual locations in the study area. The GIS based composite map was used for the prediction of soil erodibility rate, which further motivated to provide the remedial soil stabilization mechanism to diminish the soil erosion and assist enhanced soil conservation (Subramani et al., 2014; Tesfahunegn et al., 2014). Erodibility factor $(\mathrm{k} \%)$ was calculated as follows:

$$
K \%=((\% \text { Sand }+\% \text { Silt }) \div(\% \text { Clay })) \times 100
$$

A comparison study was initiated in the study area with the help of sweet gum balls, riprap (Different sizes of stones), mulch with coconut shells, bermuda grass with PAM and a control (Figure 1), to analyze the control strategies to overcome the soil erosion in the erosion prone zones as observed through the assessment.

The very idea of controlling the erodibility rate by augmenting the protective cover of the soil is motivated by the fact that more than $99 \%$ slope of the landscape of the study area is sloppy with the degree of greater than four. The rills were created in the study area with the help of manpower and the initial size of the rills was measured (Figure 4) and recorded. The triangular notches with an apex of $60^{\circ}$ were used for treating the rills. Five different rills of same size including an untreated control with four different materials used for making the protective covers were experimented initially using the triangular notches of $60^{0}$ by maintaining the actual discharge of 0.001379 $\mathrm{m}^{3} \mathrm{sec}^{-1}$.

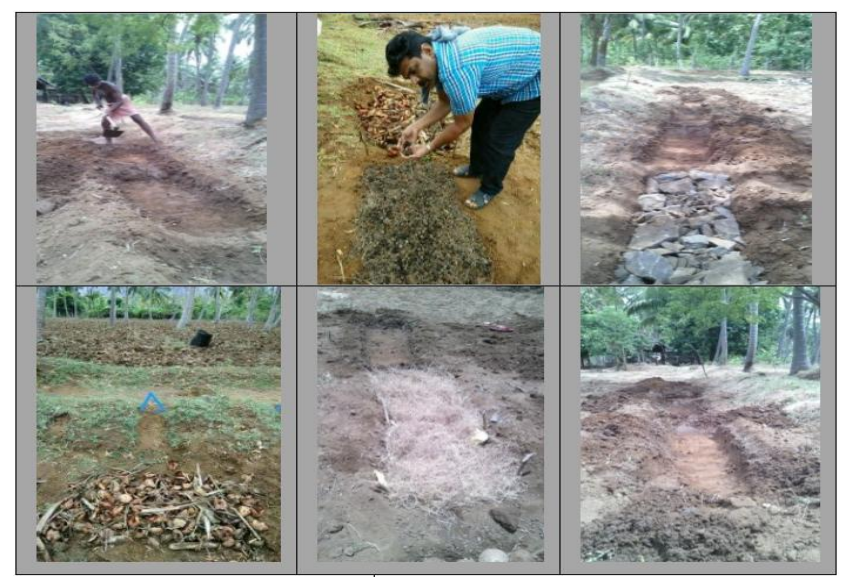

Figure-1: Rills arrangement for the treatment

Water under a constant discharge was allowed to flow over the rills for about five hours continuously and then a comparative visual observation was made upon the direct measurement to ensure the size of the rills in comparison to the initial measurement. The rills were kept under the visual observations continuously for about two years which includes two monsoon seasons for each year. The variations in the size of the rills before and after the monsoon seasons were noted and recorded to ensure the capability of the selected ingredients in controlling the soil erosion.

As shown in Figure 5 (i), Water with the said equal discharge was allowed to flow over the rills for about five hours and then a comparative visual observation was made to distinguish the size of the rills in comparison to that of rills before allowing water which is documented in Table 2 . The rills were continuously kept under the visual observations for about two years which includes two monsoon rainy seasons.

The change in the size of the rills due to the eroded soil in different seasons in the study area - The Size of the rills after Kanni Poo Season (SRAKNP), after Kumba Poo Season (SRAKUP) in the years 2015 and 2016 were measured and documented as shown in Table 3 and Figure 5 (ii-v).

\section{Results and Discussion}

It was found that the percentage finer passed through $75 \mu$ sieve is more than $30 \%$ which indicate that type of soil in the study region is sandy clay loam (SCL) according to the previous studies (Subash et al., 2016), which further confirmed in comparison with the textural triangle. As per the IS classification system, it was proven that the type of soil samples in the study 
area are absolutely poorly graded in nature. The sampled locations are found to have the highest erodibility rate with the predicted soil loss in the range of 19.56 to $22.36 \mathrm{t} \mathrm{ha}^{-1}$ year $^{-1}$. Most of the locations were found to have the high erodibility rate with the predicted soil loss in the range of 14.53 to $18.44 \mathrm{tha}^{-1}$ year ${ }^{-1}$.

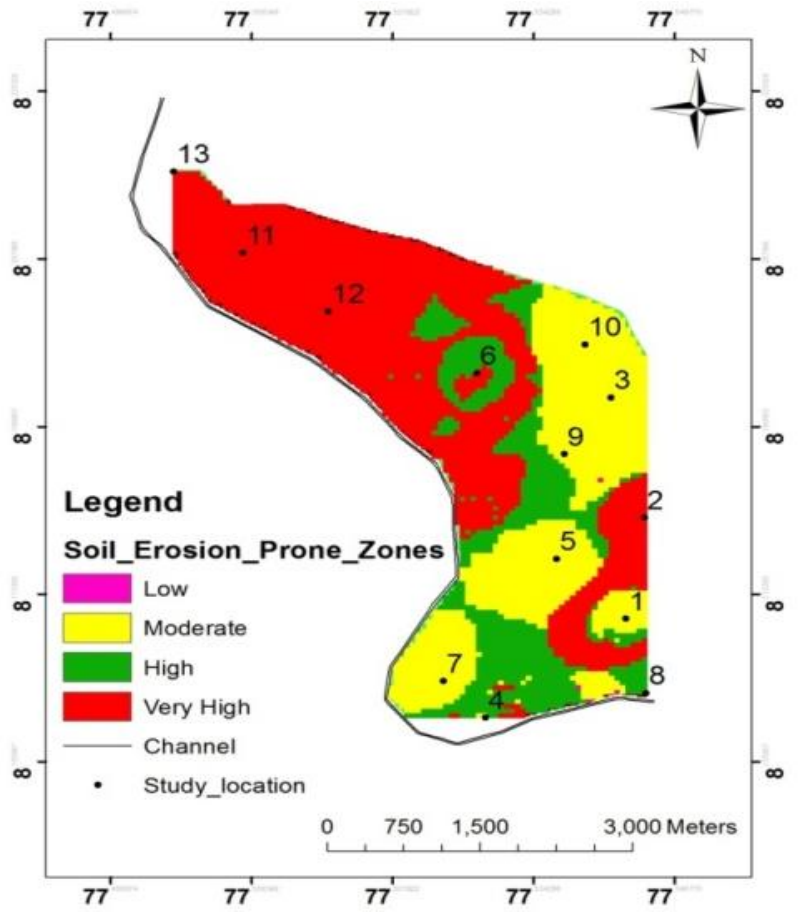

Figure-2: Composite map showing the level of soil erosion prone zones

Table-2: Visual observation of the rills against the fixed hydraulic flow

\begin{tabular}{|c|c|c|}
\hline No & Materials Used & Initial Size of Rills \\
\hline 1 & Control & $(152.4 \times 30.48 \times 30.48) \mathrm{cm}^{3}$ \\
\hline 2 & SGB & $(152.4 \times 30.48 \times 30.48) \mathrm{cm}^{3}$ \\
\hline 3 & RR & $(152.4 \times 30.48 \times 30.48) \mathrm{cm}^{3}$ \\
\hline 4 & MCS & $(152.4 \times 30.48 \times 30.48) \mathrm{cm}^{3}$ \\
\hline 5 & BGP & $(152.4 \times 30.48 \times 30.48) \mathrm{cm}^{3}$ \\
\hline No & Materials Used & Initial Size of Rills \\
\hline 1 & Control & $(121.92 \times 15.24 \times 15.24) \mathrm{cm}^{3}$ \\
\hline 2 & SGB & $(146.3 \times 25.91 \times 25.3) \mathrm{cm}^{3}$ \\
\hline 3 & RR & $(146.3 \times 25.91 \times 25.3) \mathrm{cm}^{3}$ \\
\hline 4 & MCS & $(146.3 \times 25.91 \times 25.3) \mathrm{cm}^{3}$ \\
\hline 5 & BGP & $(146.3 \times 25.91 \times 25.3) \mathrm{cm}^{3}$ \\
\hline
\end{tabular}

SGB: sweet gum ball; RR: riprap; MCS: mulch and coconut shell

BGP: Bermuda grass with pam
Table-3: Visual observation of the rills after the seasonal rainfalls (2015)

\begin{tabular}{|c|c|c|}
\hline & SRAKNP, 2015 & SRAKUP, 2015 \\
\hline UTC & $(91.4 \times 18.3 \times 21.3) \mathrm{cm}^{3}$ & $(60.96 \times 13.7 \times 13.7) \mathrm{cm}^{3}$ \\
\hline SGB & $(141.7 \times 27.4 \times 27.4) \mathrm{cm}^{3}$ & $(140.2 \times 27.4 \times 25.9) \mathrm{cm}^{3}$ \\
\hline RR & $(144.8 \times 28.9 \times 28.9) \mathrm{cm}^{3}$ & $(143.3 \times 28.9 \times 27.4) \mathrm{cm}^{3}$ \\
\hline MCS & $(141.7 \times 25.9 \times 25.9) \mathrm{cm}^{3}$ & $(140.2 \times 24.7 \times 23.8) \mathrm{cm}^{3}$ \\
\hline BGP & $(143 \times 27.4 \times 27.4) \mathrm{cm}^{3}$ & $(141.7 \times 26.5 \times 26.2) \mathrm{cm}^{3}$ \\
\hline
\end{tabular}

UTC: untreated control; SGB- sweet gum ball; RR: rip rap; MCS: Mulch with coconut shell;

BGB: bermuda grass with pam; SRAKNP: season after kanni poo; SRAKUP: season after kumba poo When comparing the changes of the rills after two rainy seasons (April - June \& Sep-Oct) of two calendar years 2015 and 2016, it was found that all those selected ingredients were effective in reducing the soil erosion.

\section{Determination of Predicted Soil Loss in the Study Area}

The estimation of soil erosion factor $(\mathrm{K})$ on each locations using RUSLE concept were very important to note the soil resistance to the erosion powers of rainfall and runoff energy (Al Rammahi and Khassaf, 2018) as well as to predict the soil loss (PSL).

The percentage of sand (PSD), the percentage of silt (PST) and the percentage of clay (PCY) were analyzed for each soil samples through sieve analysis and hydrometer analysis (Subash et al., 2016) and tabulated as shown in Table 1 . The rainfall factor $(\mathrm{H})$ was calculated as $\mathrm{R}=0.5(\mathrm{H})$, where $\mathrm{H}=$ Average rainfall intensity in the study area.

\section{Soil Stabilization by Augmenting the Protective Cover of the Soil}

According to the visual observations and measurements documented for the years 2015 and 2016 in Table 3 and 4, the treatment of the rill with riprap is found to be the most effective with $68.4 \%$ of erosion control followed by sweet gum balls, bermuda grass with PAM and mulch with the coconut shells with 57, 51.2 and $44.8 \%$ of erosion control respectively. The achievement of more than $50 \%$ soil conservation has been found with the use of sweet gum balls proves the statement of (Jody et al., 2015). The grass based achievement with more than $50 \%$ soil conservation was found by the usage of bermuda grass sod, is the best farming system and also to enhance the environmental quality as suggested (Jeremy et al., 1948). 
Subash Thanappan et al.

Additionally, the usage of mulch with coconut shells for the soil conservation has a considerable improvement closer to the other ingredients was found, which proves the statement of Bhanooduth (Lalljee, 2013).

Table-4: Visual observation of the rills after the seasonal rainfalls (2016)

\begin{tabular}{|c|c|c|}
\hline & SRAKNP, 2016 & SRAKUP, 2016 \\
\hline UTC & $(53.34 \times 10.7 \times 12.2) \mathrm{cm}^{3}$ & $(15.24 \times 6.1 \times 7.6) \mathrm{cm}^{3}$ \\
\hline SGB & $(137.8 \times 25.9 \times 25.9) \mathrm{cm}^{3}$ & $(135.6 \times 24.7 \times 24.1) \mathrm{cm}^{3}$ \\
\hline RR & $(140.8 \times 28 \times 26.2) \mathrm{cm}^{3}$ & $(140 \times 27.4 \times 25.3) \mathrm{cm}^{3}$ \\
\hline MCS & $(139 \times 23.2 \times 22.9) \mathrm{cm}^{3}$ & $(137.2 \times 22 \times 21) \mathrm{cm}^{3}$ \\
\hline BGP & $(139.6 \times 23.5 \times 23.8) \mathrm{cm}^{3}$ & $(138.7 \times 22.6 \times 23.2) \mathrm{cm}^{3}$ \\
\hline
\end{tabular}

UTC: untreated control; SGB- sweet gum ball; RR: rip rap; MCS: Mulch with coconut shell;

BGB: bermuda grass with pam; SRAKNP: season after kanni poo; SRAKUP: season after kumba poo

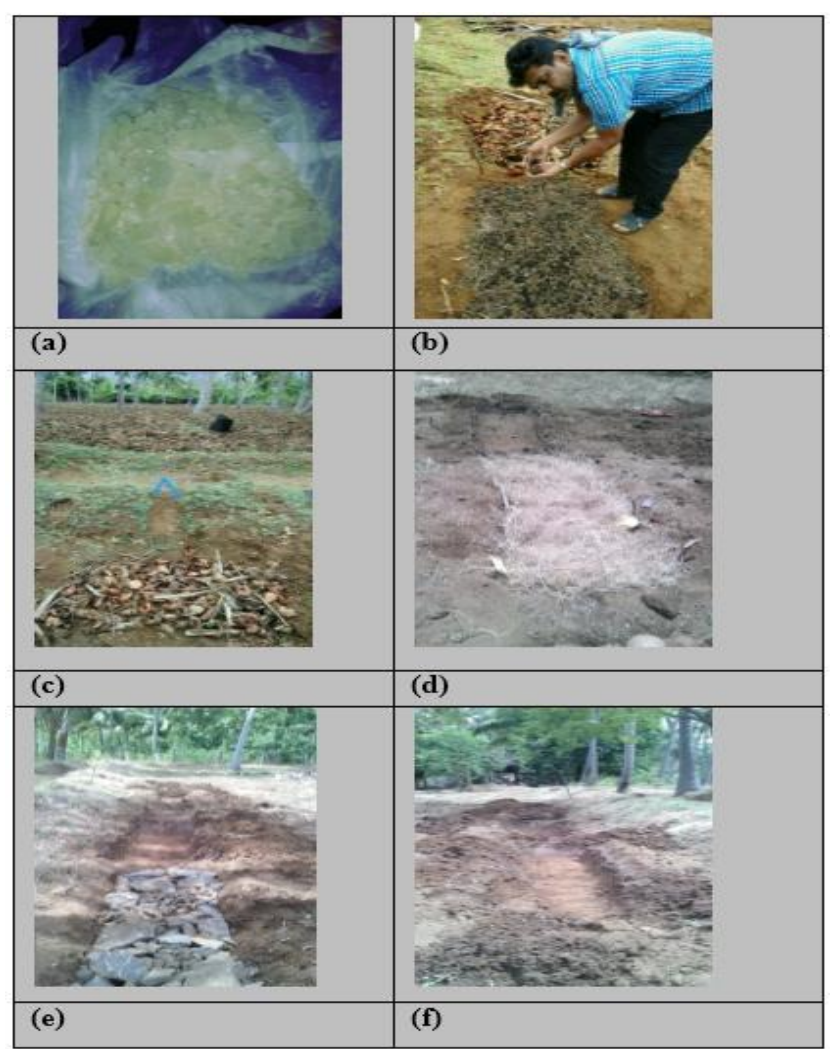

Figure-3: Protective covers under the rill treatment 3(a); PAM - powder form, 3(b) sweet gum balls in Rill-1; 3(c) mulch with coconut shells in Rill-2; 3(d) bermuda grass with PAM liquid in Rill-3; 3(e) riprap in Rill-4 and 3(d) control rill (untreated Rill -5)

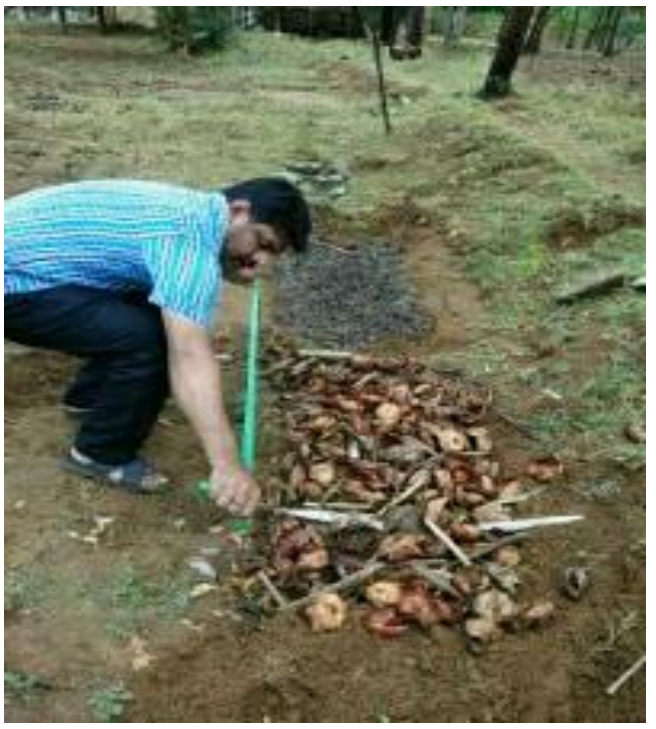

Figure-4: Measurement of initial size of the rills before treatment

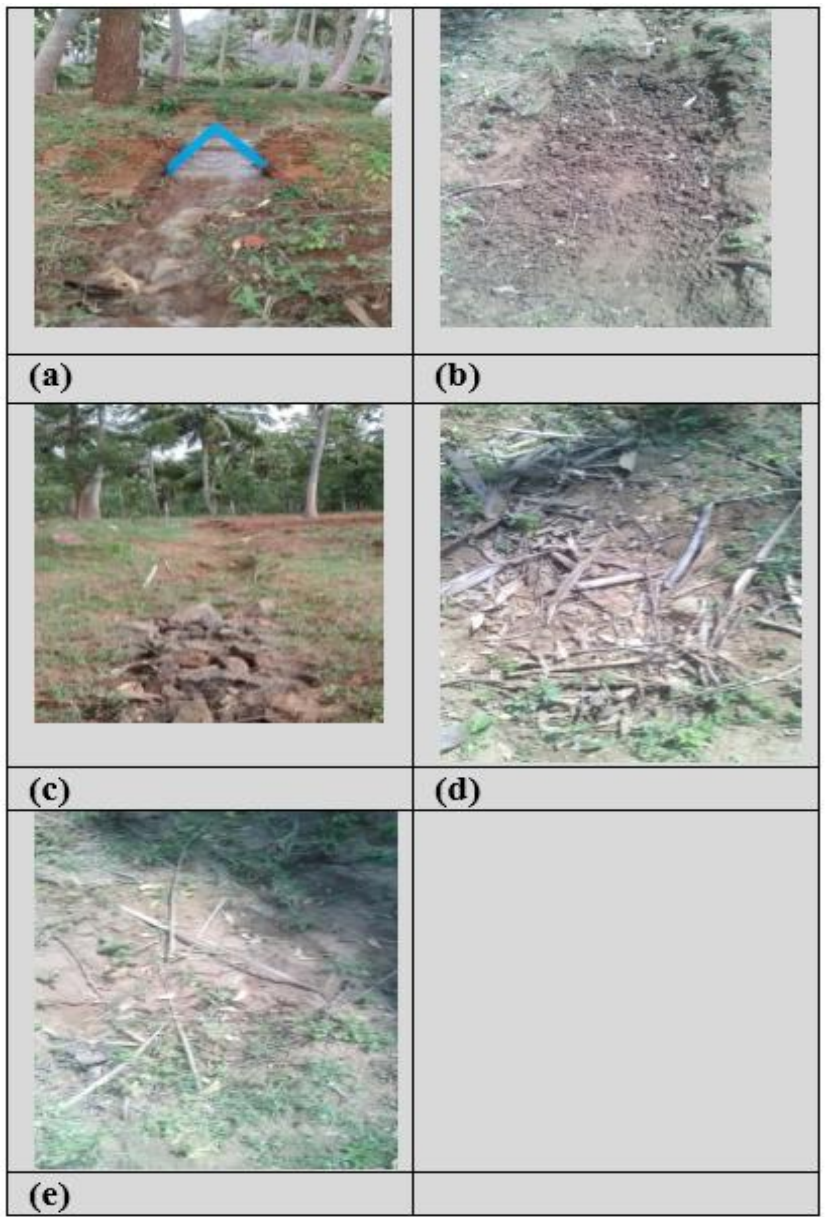

Figure-5: Changes in the size of the rills in different seasons 5(a) Hydraulic flow over a rill; 5(b) Changes in rill-1; 5(c) Changes in rill-2; 5(d) Changes in rill-3 and Changes in rill-4 


\section{Subash Thanappan et al.}

The study observed that the temporal and spatial dynamics of soil surface level and various dimensions of the rills were influenced by slope length and prolonged rainy days. The correlation of soil loss with individual rill dimensions was noted. On basis of these results rate of soil loss can now be estimated at field scale by fieldworkers in situations where sheet-rill erosion is prone within a rainfall event or season. The result upon the rill treatment would assist in formulating satisfactory and timely advice for the farmers on the effectiveness of soil and water conservation measures.

\section{Conclusion}

It is also suggested that applying the above said mechanism along with the traditional conservation methods would drastically reduce the soil erodibility rate in the study area. As the entire study area is of sloppy nature with the average degree of more than 2.5 , five innovative protective covers using different locally available ingredients were experimented to reduce the run-off, erosion and soil loss. It is strongly suggested that the protective covers can be made in the above said priority and also based on local availability which would guarantee to reduce the runoff, erosion and soil loss with the above said percentages especially for sloppy terrain.

\section{Acknowledgement}

The authors express their gratitude and thanks to Noorul Islam Centre for Higher Education (NICHE) for their support to conduct the testing on the physical and chemical characteristics of the soil samples upon the research part. Also, they express their sincere thanks to Mr. Thanappan (Gandhi), the owner of the Coconut farm, for his kind cooperation and support allowing them to perform the rill treatments throughout the research period. Sincere thanks to the Executive members of Horticulture, Thovalai, the Employees of PWD office, Mylaudy for supporting them by producing some of the primary data towards this research.

Disclaimer: None.

Conflict of Interest: None. Source of Funding: None.

\section{References}

Al Rammahi Ali HJ and Khassaf SI, 2018. Estimation of soil erodibility factor in rusle equation for euphrates river watershed using GIS. Int. J. Geomate. 14(46): 164-169. https://doi.org/10.21660/2018.46.87788

Amashi AR, Hulagabali AM, Solanki CH and Dodagowder GR, 2018. Landslide risk assessment and mitigation - a case study. Soil Dynamics Earthquake Geo. Engg. 15:249-258. Singapore: Springer.

Govers G, Merckx R, Wesemael BV and Oost KV, 2017. Soil conservation in the 21 st century: why we need smart agricultural intensification. Soil. 3:45-59. https://doi.org/10.5194/soil-3-45-2017

Jeremy WS, Alan JF and Douglas LK, 1948. Grassbased farming systems: Soil conservation and environmental quality. Grassland. 121-136.

Jody ML, Philip GC, Adams JP, Elizabeth MM and Corliss AOB, 2015. Sweetgum: a new look. Forest Biogeosci. $\quad$ Forest. 1-9. https://doi.org/10.3832/ifor1462-008

Lalljee B, 2013. Mulching as a mitigation agricultural technology against land degradation in the wake of climate change. Int. Soil Water Conser. Res. 1(3), 68-74. https://doi.org/10.1016/S20956339(15)30032-0

Lawrence GB, Fernandez IJ, Hazlett PW, Bailey SW, Ross DS, Villars TR and Koppers MM, 2016. Methods of Soil Resampling to Monitor Changes in the Chemical Concentrations of Forest Soils. J. Visualized Exp. 1-16. https://doi.org/10.3791/54815

Mehlhorn S and Alqusaireen E, 2013. Comparison of three soil erosion control treatments. American Society of Agricultural and Biological Engineers Annual International Meeting. 2013: 4611-4619. https://doi.org/10.13031/aim.20131620629

Subash T, Vincent P and Nalanth N, 2016. Geotechnical assessment of soil in erosion prone zones. Int. J. Civil Engg. Tech. 7(6): 227-240.

Subash T, Vincent P, Karuppasamy S and Kushnappa BK, 2017. Analysis of nutrient index of soil for green environment. Asian J. Chem. 29(10): 23112315. 
Subramani T, Sekar S, Kathirvel C, and Sivakumar CT, 2014. Identification of soil erosion prone zones using geomatics technology in parts of north arcot and dharmapuri district. Int. J. Engg. Res. Appl. 4(12): 150-159.

Tesfahunegn GB, Tamene L, and Vlek PLG, 2014. Soil erosion prediction using morgan-morganfinney model in a GIS environment in northern ethiopia catchment. Appl. Envirn. Soil Sci. 2014: $1-15$.

\section{Contribution of Authors}

Thanappan S: Principal investigator of the research and one who conceived idea, designed the study and wrote the manuscript

Hosamani SR: Helped for the collection of the locally available ingredients for the rill tests, and the visual observation during the study

Chandrappa MN: Helped for the preparation of thematic maps, final editing and submission of the manuscript 